\title{
Motility characteristics and membrane integrity of cryopreserved human spermatozoa
}

\author{
E. A. McLaughlin, W. C. L. Ford and M. G. R. Hull \\ University Department of Obstetrics and Gynaecology, St Michaels Hospital, \\ Southwell Street, Bristol BS2 8EG, UK
}

\begin{abstract}
Summary. The motility characteristics of washed spermatozoa from 50 normal ejaculates were measured by time-lapse photography, before and after cryopreservation. Plasma membrane integrity was assessed by the hypo-osmotic swelling test and with the supravital fluorescent dye bisbenzimide (H33258).

There was a marked decline in the percentage of progressively motile spermatozoa after cryopreservation, the extent varying widely among donors. Results were, however, consistent between different ejaculates from the same individual. The ability of spermatozoa to survive cryopreservation could not be predicted from the properties of the semen beforehand.

The mean velocity of the spermatozoa was significantly reduced after freezing, but the lateral head displacement was unaltered. There was a significant reduction in the proportion of spermatozoa with intact plasma membranes after cryopreservation and the results of the hypo-osmotic swelling test and $\mathrm{H} 33258$ tests correlated closely. There was no correlation between the declines in the percentage of motile spermatozoa, or intact spermatozoa and the sperm velocity.

We conclude that membrane rupture is not the sole cause of loss of motile spermatozoa during freezing and that the decrease in the proportion of motile spermatozoa is caused, at least in part, by a separate process from that responsible for the decrease in the average swimming speed of spermatozoa.
\end{abstract}

Keywords: spermatozoa; cryopreservation; motility; membranes; semen; donor insemination; human

\section{Introduction}

Male infertility accounts for the failure of approximately $25 \%$ of involuntarily childless couples to conceive (Hull et al., 1985). Few of these men can be successfully treated and donor insemination (DI) provides the only means for most of these couples to have children. Donor insemination is quantitatively the most important form of assisted conception and resulted in 30000 births in the USA during 1986 and 1987 (US Congress Office of Technology Assessment, 1988). Since 1986, it has been mandatory to use frozen semen for DI to ensure that it is free of human immunodeficiency virus (HIV). The fertility of frozen semen is significantly less than that of fresh semen (Watson, 1990) and the supply of donor semen is restricted. There is therefore considerable pressure to improve cryopreservation techniques for human spermatozoa.

There have been few attempts to compare the functional properties of human spermatozoa before and after freezing. Freezing causes extensive damage to membranes (Watson, 1990) and decreases the percentage of motile spermatozoa and their velocity (Critser $\mathrm{et}$ al., 1987; Keel $\mathrm{et} \mathrm{al.,}$ 1987). However, it is unclear to what extent membrane damage is responsible for the deleterious effects of cryopreservation on motility. 
Many DI donors have to be rejected because their semen fails to survive cryopreservation satisfactorily (Schroeder-Jenkins et al., 1989). The usual criterion used is that $>60 \%$ of motile spermatozoa should survive cryopreservation. This is a considerable practical disadvantage because it increases the difficulty of recruiting donors. To our knowledge, there have been no studies to characterize the properties of semen according to its ability to survive cryopreservation. We performed a standard semen analysis, motility measurements by time-lapse photography and two tests of membrane integrity on ejaculates before and after cryopreservation to quantify its deleterious effects, to define the relationship between loss of motility and membrane damage and to examine whether the ability to survive freezing could be predicted from the analysis of fresh semen. The data were stratified according to the percentage of motile spermatozoa surviving freezing. Seminal plasma constitutes half of the fluid in which the spermatozoa are frozen and the composition of the freezing medium has a major influence on cell survival. The concentration of cations in seminal plasma was therefore measured to exclude the possibility that differences in composition of seminal plasma could account for the differences in the survival of spermatozoa.

\section{Materials and Methods}

\section{Donor recruitment and semen collection}

Donors were recruited from students at the University of Bristol who applied to contribute semen to our therapeutic donor insemination programme. All were in good health and produced semen that contained at least $60 \times 10^{6}$ spermatozoa $\mathrm{ml}^{-1}$. Semen was collected by masturbation into sterile plastic containers (Richardsons, Leicester, UK) and allowed to liquefy for 30-60 min before use. Fifty ejaculates from a total of 19 donors (one to four samples each) were studied in full; in addition, the recovery of motility after freezing was measured in five to seven ejaculates from each of six selected donors.

\section{Sources of materials}

The Nicool LM 10 semi-programmable freezer was purchased from Day Impex Ltd (Colchester, UK). Liquid nitrogen refrigerators were supplied by Planar Biomed (Sunbury-on-Thames, UK). Plastic semen straws, sealing powder and goblets were obtained from Rocket of London Ltd (Watford, UK). Bisbenzamide (H33258) was purchased from Boehringer Mannheim GmBH (Lewes, UK) and all other chemicals and biochemicals were supplied by Sigma Chemical Co. Ltd (Poole, UK) or BDH Chemicals Ltd (Bristol, UK).

\section{Experimental procedure}

Within $1 \mathrm{~h}$ of production, each ejaculate was analysed for concentration, $\%$ motile and $\%$ morphologically normal spermatozoa according to the WHO protocol (World Health Organisation, 1987) except that sperm concentration was measured in a Horwell chamber. The motile normal sperm density (MNSD) was calculated from the formula MNSD $=$ concentration $\left(10^{6} \mathrm{ml}^{-1}\right) \times \%$ progressively motile $\times \%$ normal 10000 (Glazener et al., 1987). A substantial portion of the sample was mixed with an equal volume of glycerol egg-yolk citrate cryopreservative (GEYC), drawn into $0.25 \mathrm{ml}$ straws and frozen in a Nicool LM-10 freezer with an average cooling rate of $11^{\circ} \mathrm{C} \mathrm{s}^{-1}$ between +20 and $-80^{\circ} \mathrm{C}$ (McLaughlin et al., 1990), before storage under liquid nitrogen. Subsequently, the frozen semen was thawed by laying the straws on the bench top at room temperature; a standard semen analysis was performed soon afterwards.

The following procedures were performed on the remaining fresh semen and on frozen-thawed material. The sample was centrifuged at $300 \mathrm{~g}$ for $5 \mathrm{~min}$. The fresh seminal plasma was retained and stored at $-20^{\circ} \mathrm{C}$ for chemical analysis. The sperm pellet was resuspended in Biggers, Whitten and Whittingham (BWW) buffer (Aitken, 1983) containing 3\% w/v bovine serum albumin (Cohn Fraction V) and washed twice by centrifugation ( $300 \mathrm{~g}$ for $5 \mathrm{~min}$ ) before final resuspension in the same buffer at about $20 \times 10^{6}$ spermatozoa ml ${ }^{-1}$. Samples were taken for quantitative motility measurements by time-lapse photography at $37^{\circ} \mathrm{C}$ (Rees et al., 1990), and for the measurement of membrane integrity by the hypo-osmotic swelling test (Jeyendran et al., 1984) and by fluorescent staining with $\mathrm{H} 33258$ (Cross et al., 1986). The remaining sperm suspension was incubated at $37^{\circ} \mathrm{C}$ under an atmosphere of $95 \%$ air:5\% $\mathrm{CO}_{2}$ in sealed tubes for $3 \mathrm{~h}$, after which motility measurements were repeated.

\section{Analysis of seminal plasma}

These measurements were made in the Department of Clinical Pathology, St Michaels Hospital using routine procedures for clinical assays of blood plasma, using a Technicon RA 1000 autoanalyser. Sodium and 
potassium were measured with ion selective electrodes and calcium was determined spectrophotometrically after treatment with cresolphthalein. The coefficients of variation for these methods were $\mathrm{Na}^{+}, 0.6 \% ; \mathrm{K}^{+}, 1.9 \% ; \mathrm{Ca}^{2+}$, $1.5 \%$.

\section{Analysis of results}

The proportion of motile spermatozoa that survived freezing was calculated from the formula $\%$ survival $=\%$ progressively motile spermatozoa after freezing and thawing $\times 100 / \%$ progressively motile spermatozoa in fresh semen. The values were taken from the subjective estimates made on spermatozoa in whole semen or semen/GEYC, in accordance with our normal practice of assessing the suitability of semen for donor insemination. Ejaculates were allocated to the good, borderline or poor group if the \% motile spermatozoa to survive freezing and thawing was $>60,40-60$ or $<40 \%$, respectively. The significance of the effects was analysed by two- or three-way analysis of variance using the SAS Statistics Package (SAS Institute Inc, Cary. NC27512, USA).

\section{Results}

\section{Reproducibility of survival of spermatozoa}

Although there was some variation in the ability of spermatozoa in different ejaculates from the same donor to survive freezing and thawing, the within donor variation was considerably less (with one exception), than the between donor variation and the differences between several of the donors were statistically significant (Fig. 1).

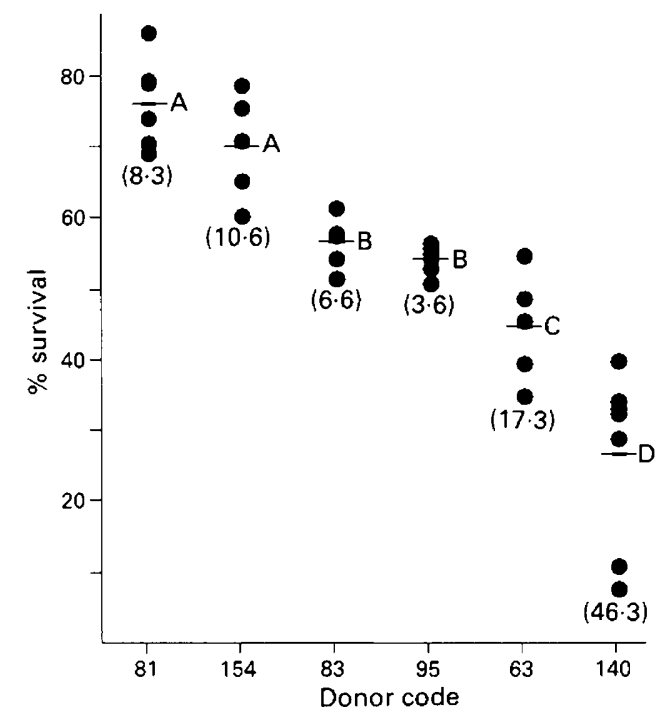

Fig. 1. Survival (\% progressively motile spermatozoa after cryopreservation: \% progressively motile spermatozoa in fresh semen) for repeated ejaculates from six human donors selected because their spermatozoa illustrated a wide range of resistance to freezing. (O) Individual values, $(-)$ means. Numbers in parentheses are the coefficients of variation $(\mathrm{CV})$. The $\mathrm{CV}$ between donors was $33 \%$. Means with different letters are significantly different $(P<0.05$, Duncan's multiple range test).

\section{Effect of freezing and thawing on standard semen analysis}

The concentration of spermatozoa was halved after cryopreservation as a result of the dilution with GEYC medium. Cryopreservation significantly reduced the percentages of progressively motile spermatozoa and morphologically normal spermatozoa. The combination of these effects produced a marked reduction in the MNSD (Table 1). 
Table 1. Human semen analysis before and after freezing for whole semen or semen-cryopreservative mixture, grouped by the percentage of motile spermatozoa to survive (means \pm SEM)

\begin{tabular}{|c|c|c|c|c|c|}
\hline & & \multicolumn{4}{|c|}{ Survival of motile spermatozoa } \\
\hline & & $\begin{array}{c}\text { Good } \\
(>60 \%)\end{array}$ & $\begin{array}{l}\text { Borderline } \\
(40-60 \%)\end{array}$ & $\begin{array}{c}\text { Poor } \\
(<40 \%)\end{array}$ & All \\
\hline Number of observations & & 18 & 17 & 15 & 50 \\
\hline Ejaculate volume (ml) & & $2.8 \pm 0.28$ & $2 \cdot 7 \pm 0 \cdot 18$ & $3 \cdot 4 \pm 0 \cdot 23$ & $2 \cdot 9 \pm 0 \cdot 14$ \\
\hline Concentration of & Fresh & $101 \pm 11.4$ & $72 \pm 5.8$ & $73 \pm 6.0$ & $83 \pm 5 \cdot 2$ \\
\hline spermatozoa $\left(10^{6} \mathrm{ml}^{-1}\right)$ & Frozen & $59 \pm 4.0$ & $\pm 3 \cdot 2$ & \pm 3.4 & \pm 2.4 \\
\hline$\%$ progressive & Fresh & $53 \pm 2 \cdot 1$ & $\pm 2 \cdot 5$ & $\pm 4 \cdot 1$ & \pm 1.7 \\
\hline spermatozoa & Frozen & \pm 1.7 & \pm 1.6 & \pm 1.8 & \pm 1.8 \\
\hline$\%$ morphologically & Fresh & $56 \quad \pm \quad 1.9$ & $55 \pm 1.8$ & \pm 2.5 & $\pm 1 \cdot 2$ \\
\hline normal spermatozoa & Frozen & $43 \pm 2 \cdot 1$ & $37 \pm 1.9$ & $\pm 2 \cdot 1$ & $\pm 1 \cdot 3$ \\
\hline Motile normal sperm & Fresh & $30 \pm 2 \cdot 6$ & $23 \pm 2 \cdot 5$ & $22 \pm 3 \cdot 0$ & $25 \pm 1.6$ \\
\hline density (MNSD)* & Frozen & $11 \pm 1 \cdot 2$ & $4.3 \pm 0.51$ & $2 \cdot 2 \pm 0.41$ & $6.0 \pm 0.71$ \\
\hline
\end{tabular}

Analysis of variance: significance of main effects $(P)$

$\begin{array}{lccc} & \text { Freezing } & \text { Group } & \text { Freezing } \times \text { Group } \\ \text { Concentration } & 0.0001 & 0.0008 & 0.7775 \\ \text { \% morphologically normal } & 0.0001 & 0.0283 & 0.1241 \\ \text { Motile normal sperm density (MNSD)* } & 0.0001 & 0.0002 & 0.9336\end{array}$

${ }^{*}$ MNSD $=$ concentration $\left(10^{6} \mathrm{ml}^{-1}\right) \times \%$ progressively motile $\times \%$ normal spermatozoa/10000 (Glazener et al. 1987).

The survival of progressively motile spermatozoa declined between the good and poor groups according to their definition and there was a greater decline in the proportion of normal spermatozoa in the poor group leading to a dramatic decline in MNSD after cryopreservation in this group (Table 1). The only difference between the groups before freezing was that the good group included some ejaculates with a very high sperm concentration so that the mean concentration was greater than in the other groups (Table 1).

\section{Properties of fresh and cryopreserved spermatozoa after washing and resuspension in BWW buffer}

With fresh spermatozoa, the percentage of progressively motile spermatozoa remained similar after washing, but with cryopreserved spermatozoa there was a substantial loss of motile spermatozoa during the washing process, which was greater in the good survival group (Tables 1 and 2). This blurred the distinction between groups. The percentage of morphologically normal spermatozoa did not change after washing in either fresh or frozen spermatozoa (Tables 1 and 2).

The percentage of spermatozoa with intact plasma membranes was significantly less after cryopreservation, but there were no differences between the survival groups before or after cryopreservation (Table 2). The results of the hypo-osmotic swelling test and the H33258 exclusion test were highly correlated $(r=0.80)$ but there was no correlation between the percentages of intact and motile spermatozoa after cryopreservation $(r=0.07)$ or between the sizes of the changes in the two parameters during cryopreservation $(r=0.08)$.

The percentage of motile spermatozoa was less when measured photographically than when assessed subjectively (Tables 2 and 3 ) but the measurements were positively correlated $(r=0 \cdot 75)$ and division into survival groups on the basis of the photographic results did not change the outcome of the experiment. The percentage of progressively motile spermatozoa declined significantly during incubation for $3 \mathrm{~h}$ at $37^{\circ} \mathrm{C}$, but by a similar proportion in fresh and cryopreserved samples (19 and 17\%, respectively). The velocity of the spermatozoa was considerably reduced after freezing but the average velocity of both fresh and cryopreserved spermatozoa remained unchanged for $3 \mathrm{~h}$. The analysis of variance revealed a significant effect of survival group on velocity and individual tests suggested that this was primarily due to the frozen spermatozoa at $0 \mathrm{~h}$ 
Table 2. Subjective assessment of fresh and cryopreserved human spermatozoa after washing and resuspension in $\mathrm{BWW}^{\mathrm{a}}$ medium. Data are grouped according to the percentage of motile spermatozoa to have survived freezing before washing (means \pm SEM)

\begin{tabular}{|c|c|c|c|c|c|c|}
\hline & & \multicolumn{5}{|c|}{ Survival of motile spermatozoa } \\
\hline & & $\underset{(>60 \%)}{\text { Good }}$ & & $\begin{array}{l}\text { Borderline } \\
(40-60 \%)\end{array}$ & $\begin{array}{c}\text { Poor } \\
(<40 \%)\end{array}$ & All \\
\hline Number of observations & & 18 & & 17 & 15 & 50 \\
\hline$\%$ progressively motile & $\begin{array}{l}\text { Fresh } \\
\text { Frozen }\end{array}$ & $\begin{array}{l}55 \pm 3 \cdot 5 \\
31 \pm 2 \cdot 5\end{array}$ & & $\begin{array}{l}54 \pm 3 \cdot 0 \\
27 \pm 2 \cdot 1\end{array}$ & $\begin{array}{l}48 \pm 3.7 \\
16 \pm 2.9\end{array}$ & $\begin{array}{l}53 \pm 2 \cdot 0 \\
25 \pm 1 \cdot 7\end{array}$ \\
\hline$\%$ morphologically & Fresh & $55 \pm 1 \cdot 8$ & & $55 \pm 1 \cdot 8$ & $53 \pm 2 \cdot 5$ & $53 \pm 1.5$ \\
\hline normal & Frozen & $42 \pm 2 \cdot 3$ & & $36 \pm 1 \cdot 7$ & $31 \pm 1.9$ & $37 \pm 1 \cdot 3$ \\
\hline$\%$ intact $\operatorname{HOST}^{\mathrm{b}}$ & $\begin{array}{l}\text { Fresh } \\
\text { Frozen }\end{array}$ & $\begin{array}{l}79 \pm 3 \cdot 0 \\
58+2 \cdot 8\end{array}$ & & $\begin{array}{l}80 \pm 3 \cdot 0 \\
57+3 \cdot 3\end{array}$ & $\begin{array}{l}75 \pm 3 \cdot 4 \\
57+2 \cdot 6\end{array}$ & $\begin{array}{l}78 \pm 1.8 \\
57+1.7\end{array}$ \\
\hline$\%$ intact $\mathrm{H} 33258^{\circ}$ & $\begin{array}{l}\text { Fresh } \\
\text { Frozen }\end{array}$ & $\begin{array}{l}74 \pm 5 \cdot 2 \\
61 \pm 3 \cdot 8\end{array}$ & & $\begin{array}{l}79 \pm 3 \cdot 8 \\
59 \pm 3 \cdot 3\end{array}$ & $\begin{array}{l}74 \pm 4.9 \\
56 \pm 3.4\end{array}$ & $\begin{array}{l}76 \pm 2 \cdot 6 \\
59 \pm 2 \cdot 0\end{array}$ \\
\hline \multicolumn{7}{|c|}{ Analysis of variance: significance of main effects $(P)$} \\
\hline $\begin{array}{l}\% \text { progressive } \\
\% \text { morphologically normal } \\
\% \text { intact HOST } \\
\% \text { intact } \mathrm{H}^{\mathrm{h}} 3258^{\mathrm{c}}\end{array}$ & & $\begin{array}{l}\text { Freezing } \\
0.0001 \\
0.0001 \\
0.0001 \\
0.0001\end{array}$ & $\begin{array}{l}\text { Group } \\
0 \cdot 0011 \\
0 \cdot 1096 \\
0.6842 \\
0.6292\end{array}$ & $\begin{array}{r}\text { Freezing } \\
0.46 \\
0.01 \\
0.62 \\
0.45\end{array}$ & & \\
\hline
\end{tabular}

${ }^{a} B W W$ : Biggers, Whitten and Whittingham buffer.

${ }^{b} \mathrm{HOST}=$ hypo-osmotic swelling test.

${ }^{\mathrm{c}} \mathrm{H} 33258=$ fluorescent stain.

$(P<0.05)$. No significant differences between groups could be detected with fresh spermatozoa or with frozen spermatozoa after incubation for $3 \mathrm{~h}$ (Table 3 ).

There was no correlation between the decline in the proportion of progressively motile spermatozoa and the decline in the average velocity of the remaining population $(r=-0.06)$. The velocities of the fresh spermatozoa had a nearly normal distribution with the mode between 60 and $70 \mu \mathrm{m} \mathrm{s}^{-1}$ as shown in Fig. 2 (note that the ordinate in Fig. 2 is nonlinear). After cryopreservation, the distribution was skewed towards lower velocities with a mode between 20 and $30 \mu \mathrm{m} \mathrm{s}^{-1}$, although a small population of fast swimming spermatozoa remained (Fig. 2). Lateral head displacement was not affected by freezing, incubation time or survival group (Table 3 ).

The concentrations of ions in seminal plasma were similar, irrespective of the survival of spermatozoa from the same ejaculate after cryopreservation (Table 4).

\section{Discussion}

The results obtained (Fig. 1) confirm that there is a wide variation among individuals in the capacity of their spermatozoa to survive freezing, but that survival is comparatively consistent between different ejaculates from the same individual. It is therefore probable that the ability of semen from an individual to withstand cryopreservation depends on some consistent property of the spermatozoa or seminal plasma. Once the cause of poor freezing is known, it might be possible to modify cryopreservation procedures to overcome it and so increase the proportion of potential semen donors who could be accepted.

Cell damage during freezing is usually ascribed to membrane rupture caused by the formation of intracellular ice crystals during rapid cooling, or by osmotic effects, or mechanical force from extracellular ice during slow cooling (see Mazur, 1984). Here we measured membrane integrity by two independent methods: the hypo-osmotic swelling test, which relies on the swelling of the tail to demonstrate membrane integrity, and the exclusion of $\mathrm{H} 33258$ where the nuclei of spermatozoa 
Table 3. Motility characteristics determined by time-lapse photography of fresh and cryopreserved human spermatozoa after washing and resuspension. Measurements were made soon after resuspension in $\mathrm{BWW}^{\mathrm{a}}$ buffer and after $3 \mathrm{~h}$ incubation at $37^{\circ} \mathrm{C}$ under $95 \%$ air $/ 5 \% \mathrm{CO}_{2}$. Data are grouped according to the percentage of motile spermatozoa to have survived freezing before washing (means \pm SEM)

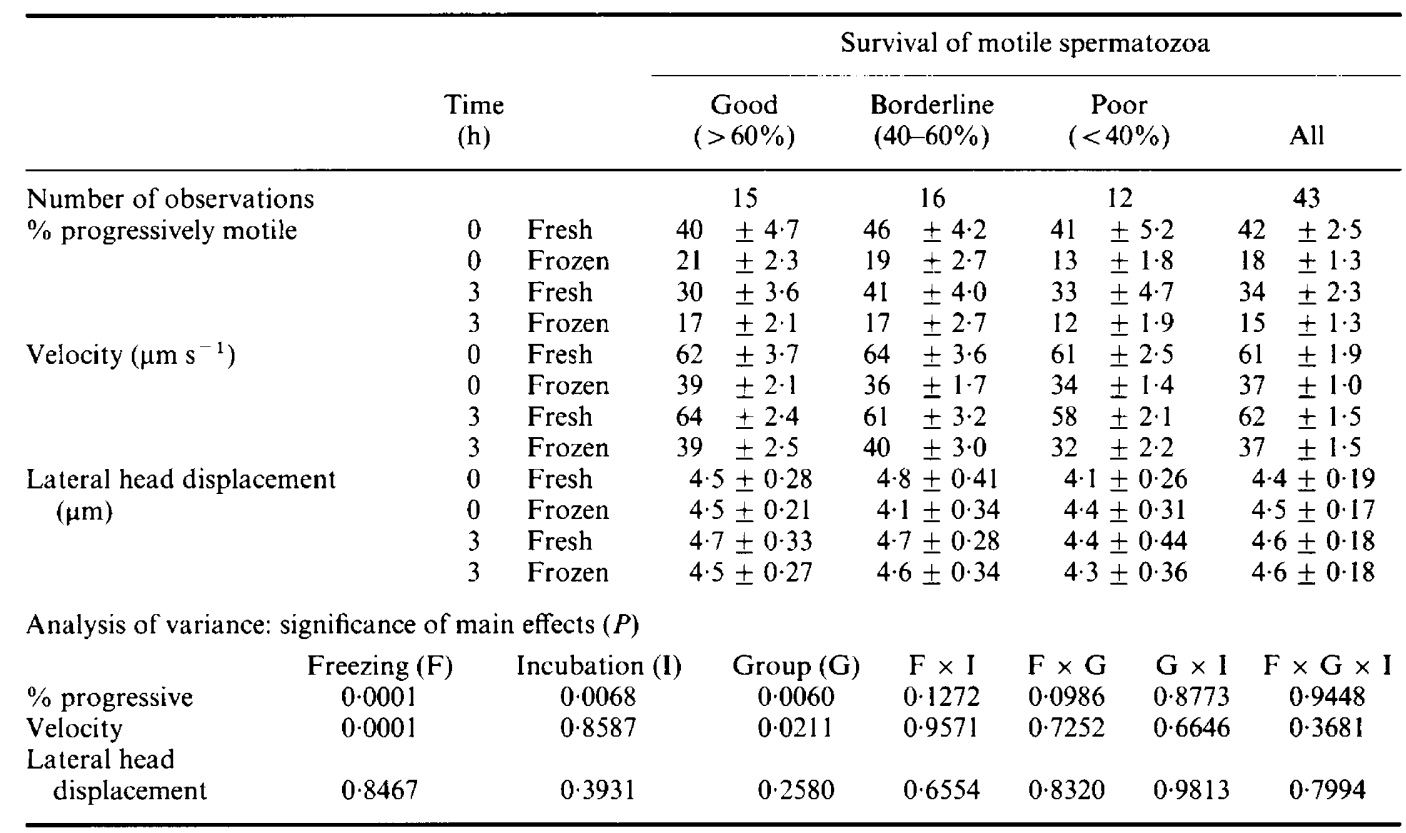

${ }^{a}$ BWW: Biggers, Whitten and Whittingham buffer.
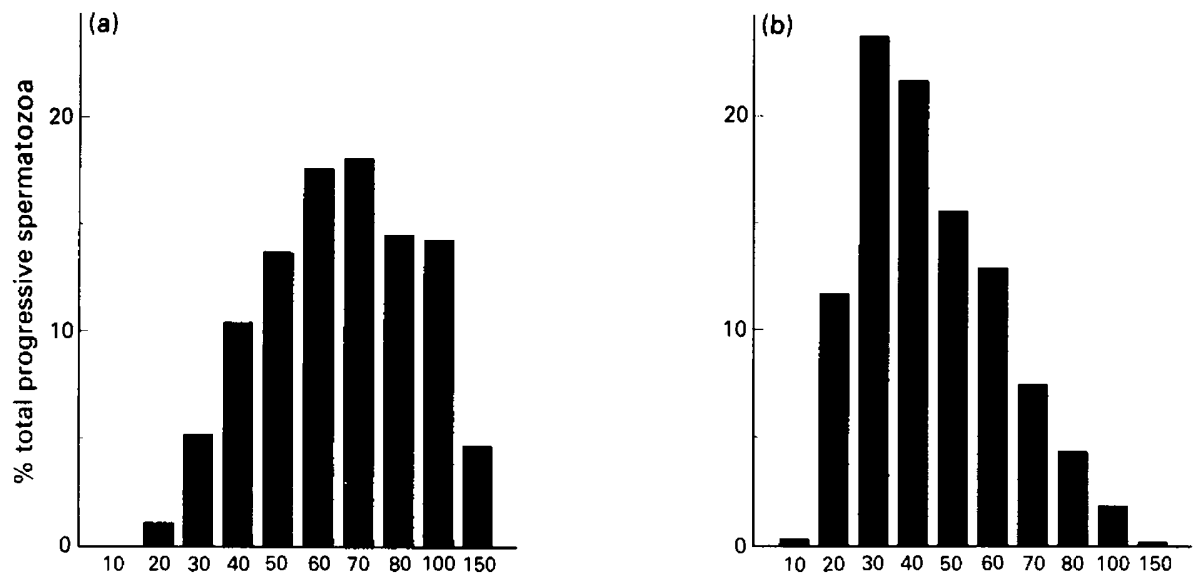

Velocity $\left(\mu \mathrm{m} \mathrm{s}^{-1}\right)$

Fig. 2. Distribution of velocities of (a) 3405 fresh and (b) 1705 frozen human spermatozoa from 50 ejaculates. Only the upper boundary of each range is shown, e.g. 50 represents spermatozoa with a velocity of $>40$ but $\leqslant 50 \mu \mathrm{m} \mathrm{s}^{-1}$.

with damaged membranes are stained. The close correlation between the two methods, which focus on different compartments within the spermatozoa, suggests that the estimates are correct. As expected there was a significant decrease in the percentage of intact spermatozoa after freezing and 
Table 4. The concentrations ( $\mathrm{mmol} \mathrm{1}^{-1}$ ) of sodium, potassium and calcium in seminal plasma from ejaculates containing spermatozoa with different abilities to survive cryopreservation (means \pm SEM)

\begin{tabular}{lcccc}
\hline & \multicolumn{3}{c}{ Survival of motile spermatozoa } \\
\cline { 2 - 5 } & Good $(>60 \%)$ & Borderline $(40-60 \%)$ & Poor $(<40 \%)$ \\
\hline Number of observations & 16 & 16 & 15 \\
Sodium & $122 \pm 1.8$ & $122 \pm 2.0$ & $121 \quad \pm 1.2$ \\
Potassium & $30 \pm 1.4$ & $27 \pm 1.2$ & $27 \pm 1.4$ \\
Calcium & $6.3 \pm 0.6$ & $5 \cdot 3 \pm 0.5$ & $5.7 \pm 0.6$ \\
\hline
\end{tabular}

thawing. However, there was no significant correlation between the percentages of intact spermatozoa and progressively motile spermatozoa or between the changes in the two parameters during freezing and thawing. The considerable loss of progressively motile spermatozoa upon dilution from GEYC into BWW buffer was probably due to osmotic stress and complicates the interpretation of the data. It is clear, however, that membrane rupture cannot be the only process that contributes to the loss of motility by human spermatozoa during cryopreservation. Nevertheless, the assays used here can detect only damage sufficient to render the membrane permeable to solutes and it is possible that more subtle effects on membrane structure, such as can be detected by electron microscopy (see Watson, 1990), may be involved.

Cryopreservation decreased the average velocity of the progressively motile spermatozoa by about $40 \%$. This is similar to the decrease of about $30 \%$ reported by Keel et al. (1987), who measured motility at room temperature. The decline in velocity was significantly greater in the poor than in the borderline or good survival groups but there was no correlation between the decline in the percentage of progressively motile spermatozoa and the decrease in their average velocity. This suggests that the slowing and the rendering immotile of spermatozoa during cryopreservation do not necessarily share a common mechanism. The observations cannot be accounted for by a consistent slowing of every spermatozoon during cryopreservation, so that those spermatozoa that were swimming slowly beforehand become immotile afterwards. The simplest possible explanation is that loss of motility could result either from membrane damage or from excessive slowing and that the proportion due to each factor varied between ejaculates, so that neither factor correlated with the decline in the percentage of progressive spermatozoa. However, it is more likely that other damage processes are involved.

The concentration of spermatozoa that could swim at $>50 \mu \mathrm{m} \mathrm{s} \mathrm{s}^{-1}$ declined from $23 \times 10^{6} \mathrm{ml}^{-1}$ before cryopreservation to $1.6 \times 10^{6} \mathrm{ml}^{-1}$ afterwards (calculation based on photographically measured motility characteristics and sperm concentration in whole semen or semen/GEYC mixture). Sperm velocity has been shown to be related to the fertility of cryopreserved ejaculates used for DI (Irvine \& Aitken, 1986; Holt et al., 1989) or for in vitro fertilization (Holt et al., 1985; Hinting et al., 1988; Bongso et al., 1989) or in natural intercourse (Vantman et al., 1989). Such a large decline in the concentration of vigorously motile spermatozoa is probably a major factor contributing to the decreased fertility of frozen compared with fresh spermatozoa.

None of the characteristics of fresh semen investigated in these experiments could predict its ability to survive cryopreservation. Although the concentration of major cations in seminal plasma was not correlated with freeze survival, this is a complex fluid and it remains unclear if the ability to survive cryopreservation is determined by properties of the seminal plasma, the spermatozoa or both.

This work was supported by grant no. F1/87 from the Birthright Trust. We are grateful to C. Pennock and his colleagues in the Department of Chemical Pathology, St Michaels Hospital, for the analysis of cations in seminal plasma. 


\section{References}

Aitken, R.J. (1983) The zona free hamster egg penetration test. In Male Infertility, pp. 75 -86. Ed. T. B. Hargreave. Springer Verlag, Berlin.

Bongso, T.A., Ng, S.C., Mok, H., Lim, M.N., Teo, H.L., Wong, P.C. \& Ratnam, S.S. (1989) Effects of sperm motility on human in vitro fertilization. Archives of Andrology 22, 185-190.

Critser, J.K., Arneson, B.W., Asker, D.V., Huse-Benda, A.R. \& Ball, G.D. (1987) Cryopreservation of human spermatozoa. II. Post thaw chronology of motility and of zona-free hamster ova penetration. Fertility and Sterility 47, 980-984.

Cross, N.L., Morales, P., Overstreet, J.W. \& Hanson, F.W. (1986) Two simple methods for detecting acrosome reacted human sperm. Gamete Research 15, 213-226.

Glazener, C.M.A., Kelly, N.J., Weir, M.J.A., David, J.S.E., Cornes, J.S. \& Hull, M.G.R. (1987) The diagnosis of male infertility - a prospective time specific study of conception rates related to seminal analysis and post coital sperm mucus penetration and survival in otherwise unexplained infertility. Human Reproduction 2, 665-671.

Hinting, A., Comhaire, F. \& Schoonjans, B.S. (1988) Capacity of objectively assessed sperm motility characteristics in differentiating between semen of fertile and subfertile men. Fertility and Sterility 50, 635-639.

Holt, W.V., Moore, H.D.M. \& Hillier, S.G. (1985) Computer assisted measurement of sperm swimming speed in human semen: correlation of results with in vitro fertilization assays. Fertility and Sterility 44, $112-119$.

Holt, W.V., Shenfield, F., Leonard, T., Hartman, T.D., North, R.D. \& Moore, H.D.M. (1989) The value of sperm swimming speed measurements in assessing the fertility of human frozen spermatozoa. Human Reproduction 4, 292-297.

Hull, M.G.R., Glazener, C.M.A., Kelly, N.J., Conway, D.I., Foster, P.A., Hinton, R.A., Coulson, C., Lambert, P.A., Watt, E.M. \& Desai, K.M. (1985) Population study of causes, treatment and outcome of infertility. British Medical Journal 291, 1693-1697.

Irvine, D.S. \& Aitken, R.J. (1986) Predictive value of in vitro sperm function tests in the context of an AID service. Human Reproduction 1, 539-545.
Jeyendran, R.S., Van der Ven, H.H., Perez-Palaez, M., Crabo, B.G. \& Zaneveld, L.J.D. (1984) Development of an assay to assess the functional integrity of the human sperm membrane and its relationship to other semen characteristics. Journal of Reproduction and Fertility 70, 219-228.

Keel, B.A., Webster, B.W. \& Roberts, D.K. (1987) Effects of cryopreservation on the motility characteristics of human spermatozoa. Journal of Reproduction and Fertility 81, 213-220.

McLaughlin, E.A., Ford, W.C.L. \& Hull, M.G.R. (1990) A comparison of the freezing of human semen in the uncirculated vapour above liquid nitrogen and in a commercial semi-programmable freezer. Human Reproduction 5, 724-728.

Mazur, P. (1984) Freezing of living cells: mechanisms and implications. American Journal of Physiology 247, C125-C142.

Rees, J.M., Ford, W.C.L. \& Hull, M.G.R. (1990) The effect of caffeine and pentoxifylline on the motility and metabolism of human spermatozoa. Journal of Reproduction and Fertility 90, 147-156.

Shroeder-Jenkins, M. \& Rothman, S.A. (1989) Causes of donor rejection in a sperm banking program. Fertility and Sterility 51, 903-906.

US Congress, Office of Technology Assessment (1988) Artificial Insemination: Practice in the United States: Summary of a 1987 Survey-Background paper, OTA-BP-BA-48. US Government Printing Office: Washington DC, USA

Vantman, D., Denison, L., Banks, S.M., Sherins, R.J. \& Koukoulis, G. (1989) Assessment of sperm motility characteristics from fertile and infertile men using a fully automated computer assisted semen analyser. Fertility and Sterility 51, 156-161.

Watson, P.F. (1990) Artificial insemination and the preservation of semen. In Marshall's Physiology of Reproduction 4th Edition (Vol. 2), pp. 747-869. Ed. G. E. Lamming. Churchill Livingstone, Edinburgh.

World Health Organisation (1987) WHO Laboratory Manual for the Examination of Human Semen and Semen-cervical Mucus Interaction (2nd Edn). Cambridge University Press, Cambridge.

Received 8 April 1991 